\title{
Retinal laser lenses: magnification, spot size, and field of view
}

Department of Ophthalmology, Kansas University Medical Center, Kansas City, Kansas, USA M A Mainster

Ocular Instruments Inc, Bellevue, Washington, USA

J L Crossman

G L Heacock

Correspondence to: Martin A Mainster, MD, Department of Ophthalmology, Kansas University Medical Center, 39th and Rainbow Boulevard, Kansas City, Kansas 66103, USA.

Accepted for publication 20 September 1989

\author{
Martin A Mainster, Janet L Crossman, Phillip J Erickson, Gregory L Heacock
}

\begin{abstract}
Proper use of ophthalmoscopic contact lenses for retinal photocoagulation requires knowledge of their comparative magnification, spot size, and field of view. We determined these parameters for four commonly used lenses, using data measured from optical components of the lenses and a commonly used photocoagulator slit-lamp and spot size changer. A Krieger lens has $8 \%$ more working field of view and $29 \%$ less magnification than a Goldmann lens. A Panfundoscope lens has $84 \%$ more working field of view and $24 \%$ less magnification than a Goldmann lens. A Mainster lens has $58 \%$ more working field of view and $3 \%$ more magnification than a Goldmann lens. For Goldmann, Krieger, Panfundoscope, and Mainster lenses, respectively, retinal spot size is $8 \%, 53 \%, 41 \%$, and $5 \%$ greater than photocoagulator spot size settings. The field of view of each lens is increased in myopic and decreased in hyperopic patients. Anterior segment irradiance is higher than retinal irradiance for $1000 \mu \mathrm{m}$ spot size settings with a Panfundoscope or Mainster lens, and this setting should be avoided, especially in patients with hazy ocular media.
\end{abstract}

Retinal temperature increase from laser photocoagulation is proportional to retinal irradiance, the laser power per unit area reaching the retinal surface. ${ }^{2}$ Decreasing laser spot size increases retinal irradiance and tissue effects for a particular combination of power and exposure duration settings. Thus, knowledge of laser spot size is important for ensuring safety and reproducibility of clinical results from retinal photocoagulation.

Laser photocoagulators have calibrated spot size selectors, but the actual retinal spot size they produce depends on the particular contact lens used for laser beam delivery and the patient's refractive error. New contact lenses have been introduced in recent years to facilitate ophthalmoscopy during retinal photocoagulation..$^{3-9}$ Each lens has its own advantages, but optimal lens usage requires knowledge of comparative lens magnification, spot size, and field of view. These data were determined from computerised ray tracing models of the human eye, four commonly used ophthalmoscopic lenses, and a standard slit-lamp and photocoagulator spot size changer.

Materials and methods

Goldmann, Krieger, Panfundoscope, and Mainster ophthalmoscopic contact lenses were studied. Table I summarises their characteristics. Optical parameters of a Zeiss 30 SL-M slitlamp (Carl Zeiss, Oberkochen, West Germany) were used for field of view calculations, and those of a Coherent Model 920 photocoagulator spot size changer (Coherent Medical Division, Palo Alto, CA) were used for spot size calculations. The spot size changer is parfocal for 50 and 100 $\mu \mathrm{m}$ spot sizes, and defocuses for larger spot sizes.

The radius of curvature and back focal length were measured for each ophthalmoscopic lens, slit-lamp, and spot-size changer component with a Zygo Mark I interferometer (Zygo, Middlefield, CT). Centre thicknesses, apertures, and lens separations were measured directly. A modified Le Grand-El Hage unaccommodated theoretical model eye ${ }^{10}$ was used in all calculations, with an anterior corneal radius of 7.824 $\mathrm{mm}$, and a conic constant of -0.870852 to correct for axial spherical aberrations ${ }^{11}$ of the human eye. Calculations were performed with the Super-Oslo optical design program (Sinclair Optics, Inc, Fairport, NY).

\section{Results}

Goldmann and Krieger lenses produce erect, virtual ophthalmoscopic images, while Panfundoscope and Mainster lenses have inverted, real images. The orientation, axial location, and magnification of the ophthalmoscopic image of each lens is illustrated in Figures $1-4$.

Magnification and field of view are critical parameters for determining which lens is best for a particular clinical problem. Table II presents computed magnification and field of view for the four lenses. The lateral magnification was determined for each lens from ray tracing studies with ophthalmoscopic lens and model eye parameters. Positive and negative lateral magnification connote erect and inverted image orientation respectively. Relative magnification is the absolute value of lateral magnification divided by the lateral magnification of a Goldmann lens. It indicates that Goldmann and Mainster lenses have similar magnification, but that Panfundoscope and Kreiger lens magnification is much smaller. Axial magnification is the square of lateral magnification.

Field of view computations were performed for each slit-lamp, ophthalmoscopic lens, and model eye system. These calculations were carried out relative to the nodal point of the eye model on the assumption of a $7 \mathrm{~mm}$ dilated pupil diameter. Instantaneous field of view is the maximum field observable at one time without tilting the lens. Working field of view is the 
TABLE I Ophthalmoscopic laser contact lenses

\begin{tabular}{|c|c|c|c|c|}
\hline Parameter & Goldmann ${ }^{\star}$ & Kriegent & Panfundoscope $\ddagger$ & Mainstert \\
\hline $\begin{array}{l}\text { Anterior surface } \\
\text { Power§ } \\
\text { Image type } \\
\text { Image location }\end{array}$ & $\begin{array}{l}\text { Flat } \\
-67 \\
\text { Virtual, erect } \\
\text { Posterior capsule }\end{array}$ & $\begin{array}{l}\text { Concave, spherical } \\
-92 \\
\text { Virtual, erect } \\
\text { Vitreous humour }\end{array}$ & $\begin{array}{l}\text { Convex, spherical } \\
+85 \\
\text { Real, inverted } \\
\text { Biconvex lens }\end{array}$ & $\begin{array}{l}\text { Convex, aspherica } \\
+61 \\
\text { Real, inverted } \\
\text { Air }\end{array}$ \\
\hline
\end{tabular}

^Haag-Streit, Bern, Switzerland. †Ocular Instruments, Bellevue, WA, USA. ‡Rodenstock, Munich West Germany. $\$$ Refractive power in dioptres of the entire ophthalmoscopic lens system in air, as determined from direct measurement.

maximum field obtainable with a $15^{\circ}$ tilt to either side of the optical axis. For each lens the field stop (which limits the field of view ${ }^{1213}$ ) was the patient's iris for pupil diameters up to $7 \mathrm{~mm}$. The aperture stop (which limits the amount of light reaching the image $^{1213}$ ) is located in the slitlamp's telescopic section.

Table II shows that the inverted image lenses

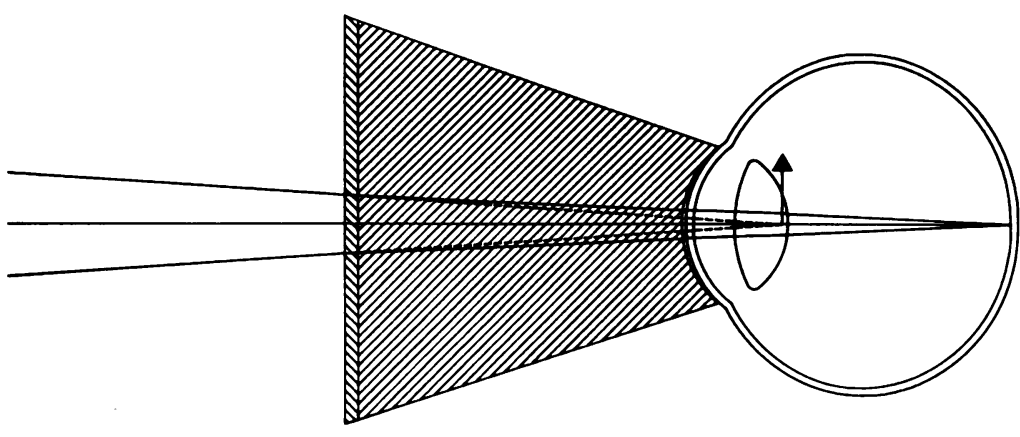

Figure 1: The Goldmann lens has a flat anterior surface and produces an erect, virtual ophthalmoscopic image located near the posterior surface of the crystalline lens.

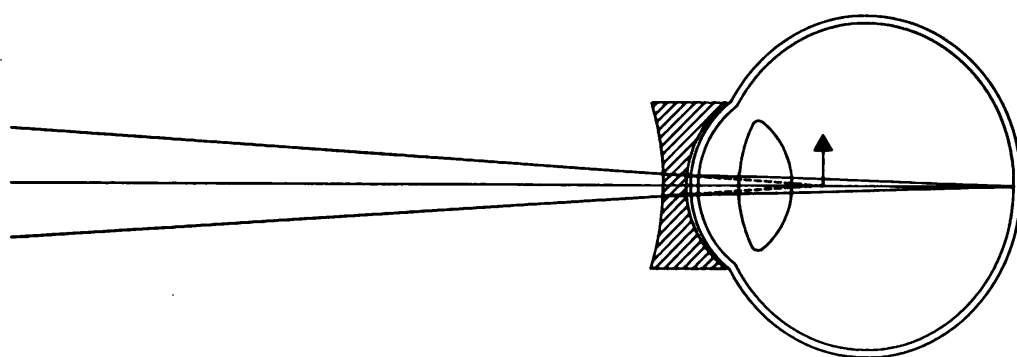

Figure 2: The Krieger lens has a concave anterior surface and produces an erect, virtual ophthalmoscopic image located in the anterior vitreous humour.

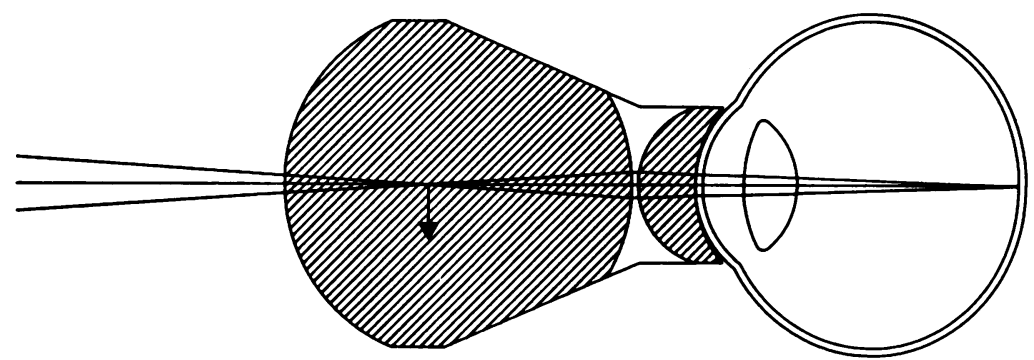

Figure 3: The Panfundoscope lens has a biconvex, spherical anterior lens element and produces an inverted, real image inside the biconvex lens.

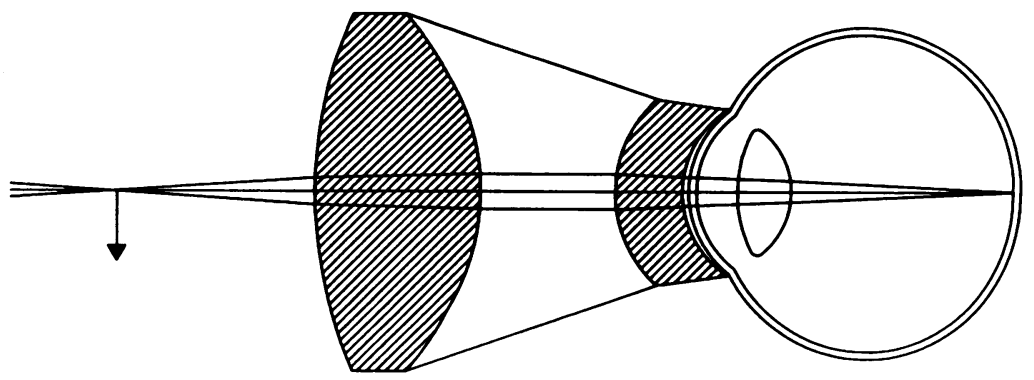

Figure 4: The Mainster lens has a biconvex, aspherical anterior lens element and produces an inverted, real image anterior to the biconvex lens. have a considerably greater field of view than the erect image lenses. Table III presents the results of similar magnification and field of view calculations carried out for \pm 3 dioptre axial ametropia. Results are presented as percentage differences from emmetropic eye findings, with positive and negative percentages indicating higher or lower values respectively. Ametropia has little effect on the magnification of the erect image ophthalmoscopic lenses, but the magnification of inverted image lenses is decreased in myopia and increased in hyperopia. Field of view is increased in myopia and decreased in hyperopia for each of the lenses.

Spot size calculations were performed for optical systems consisting of the spot size charger, an ophthalmoscopic lens, and the model eye. Table IV presents spot size changer settings and the spot sizes they produce at the posterior surfaces of the cornea, crystalline lens, and neural retina. It shows that spot size settings are reasonably accurate for Goldmann and Mainster lenses, but that retinal spot size is greater than the setting by approximately $40 \%$ and $50 \%$ for the Panfundoscope and Kreiger lenses, respectively. Table IV also shows that, for $1000 \mu \mathrm{m}$ settings, corneal spot size is $60 \%$ and $23 \%$ smaller than retinal spot size for the Panfundoscope and Mainster lenses respectively. Thus, for a $1000 \mu \mathrm{m}$ setting, corneal irradiance may be up to 6.2 or 1.7 times greater than retinal irradiance for a Panfundoscope or Mainster lens, respectively.

\section{Discussion}

The three-mirror Goldmann lens has been a standard ophthalmoscopic lens since biomicroscopic laser photocoagulation began, providing excellent posterior pole magnification as well as peripheral retinal observation through internal reflecting surfaces. The chief disadvantage of the Goldmann lens, its limited field of view, prompted development of the three other ophthalmoscopic lenses discussed in this paper. Each lens is a different choice in balancing field of view with ophthalmoscopic image magnification.

The concave surfaced Krieger lens was developed in 1966, and various modifications have been introduced subsequently. ${ }^{89}$ The Krieger lens provides an erect, virtual image as does the Goldmann lens, but its ophthalmoscopic image is displaced posteriorly from the posterior capsule into the anterior vitreous (see Figs 1 and 2). As shown in Table II, the Krieger lens has an $8 \%$ greater working field of view than the Goldmann lens, but this is accomplished at a substantial $29 \%$ decrease in lateral magnification.

Introduction of the Panfundoscope lens in 1969 increased the ease and safety of panretinal photocoagulation. ${ }^{46}$ The Panfundoscope lens produces an inverted, real image located in its spherical biconvex anterior lens element, as shown in Figure 3.

The Panfundoscope lens has a working field of view $84 \%$ greater than that of the Goldmann lens, accomplished at a $24 \%$ reduction in lateral magnification. This reduced magnification is not 
TABLE II Magnification and field of view for laser ophthalmoscopic contact lenses

\begin{tabular}{lcccc}
\hline Parameter & Goldmann & Krieger & Panfundoscope & Mainster \\
\hline Lateral magnification & +0.93 & +0.66 & -0.71 & -0.96 \\
Relative magnification & 1.00 & 0.71 & 0.76 & 1.03 \\
Axial magnification & 0.86 & 0.43 & 0.51 & 0.92 \\
Instantaneous field of view $^{\star}$ & $\pm 18^{\circ}$ & $\pm 21^{\circ}$ & $\pm 60^{\circ}$ & $\pm 45^{\circ}$ \\
${\text { Working field of view (with } 15^{\circ} \text { tilt) }}^{\star} \pm 38^{\circ}$ & $\pm 41^{\circ}$ & $\pm 70^{\circ}$ & $\pm 60^{\circ}$ \\
\hline
\end{tabular}

${ }^{\star}$ Half-field angle.

TABLE III Change in magnification and working field of view in patients with axial myopia and hyperopia

\begin{tabular}{lcccc}
\hline Parameter & Goldmann & Krieger & Panfundoscope & Mainster \\
\hline Magnification (myope, -3 D) & 0 & $-1 \cdot 5 \%$ & $-4 \cdot 2 \%$ & $-5 \cdot 2 \%$ \\
Magnification (hyperope, +3 D) & 0 & 0 & $+5 \cdot 6 \%$ & $+4 \cdot 2 \%$ \\
Field of view (myope, -3 D) & $+5 \cdot 3 \%$ & $+4 \cdot 9 \%$ & $+8 \cdot 6 \%$ & $+6 \cdot 7 \%$ \\
Field of view (hyperope, +3 D) & $-5 \cdot 3 \%$ & $-2 \cdot 4 \%$ & $-5 \cdot 7 \%$ & $-6 \cdot 7 \%$ \\
\hline
\end{tabular}

a disadvantage in panretinal photocoagulation, but it limits the usefulness of the Panfundoscope lens in procedures requiring high lateral and axial magnification, such as photocoagulation for choroidal neovascularisation. Increasing biomicroscopic magnification cannot compensate for reduced ophthalmoscopic image magnification, because it cannot increase the resolution of the ophthalmoscopic image.

The Mainster lens was introduced in 1986, providing higher magnification but a smaller field of view than the Panfundoscope lens. As shown in Figure 4, the Mainster lens produces an inverted, real image located in front of its biconvex aspheric anterior lens element. Laser beam distortion at the edge of the field of view is minimised by the aspheric element. Since the ophthalmoscopic image is anteriorly displaced, however, using the Mainster lens with older slitlamps of reduced anteroposterior travel (for example, Zeiss model 125 ) may require moving a hyperopic or exophthalmic patient's forehead several millimetres backwards from the headrest.

The Mainster lens has a working field of view

TABLE IV Laser beam diameter at the cornea, lens, and retina versus photocoagulator spot size setting, for the laser beam focused on the retina ${ }^{\star}$

\begin{tabular}{|c|c|c|c|c|c|}
\hline \multirow{2}{*}{$\begin{array}{l}\text { Tissue } \\
\text { (posterior } \\
\text { surface) }\end{array}$} & \multirow{2}{*}{$\begin{array}{l}\text { Spot size } \\
\text { setting } \\
(\mu \mathrm{m})\end{array}$} & \multicolumn{4}{|c|}{ Tissue spot size $(\mu m)$} \\
\hline & & Goldmann & Krieger & Panfundoscope & Mainster \\
\hline Cornea & $\begin{array}{r}100 \\
200 \\
500 \\
1000\end{array}$ & $\begin{array}{l}1335 \\
1321 \\
1432 \\
1793\end{array}$ & $\begin{array}{r}979 \\
1004 \\
1187 \\
1616\end{array}$ & $\begin{array}{l}959 \\
866 \\
703 \\
567\end{array}$ & $\begin{array}{r}1285 \\
1164 \\
960 \\
804\end{array}$ \\
\hline Lens & $\begin{array}{r}100 \\
200 \\
500 \\
1000\end{array}$ & $\begin{array}{l}1048 \\
1071 \\
1256 \\
1697\end{array}$ & $\begin{array}{r}791 \\
857 \\
1138 \\
1700\end{array}$ & $\begin{array}{l}760 \\
733 \\
742 \\
859\end{array}$ & $\begin{array}{r}1000 \\
941 \\
887 \\
934\end{array}$ \\
\hline Retina & $\begin{array}{r}100 \\
200 \\
500 \\
1000\end{array}$ & $\begin{array}{r}108 \\
216 \\
541 \\
1081\end{array}$ & $\begin{array}{r}153 \\
306 \\
764 \\
1529\end{array}$ & $\begin{array}{r}141 \\
282 \\
704 \\
1409\end{array}$ & $\begin{array}{r}105 \\
210 \\
524 \\
1048\end{array}$ \\
\hline
\end{tabular}

^For example, with the laser beam focused on the retina and a 1000 $\mu \mathrm{m}$ photocoagulator spot size setting, beam diameter with a Panfundoscope lens will be $567 \mu \mathrm{m}, 859 \mu \mathrm{m}$, and $1409 \mu \mathrm{m}$ at the posterior surfaces of the cornea, lens, and retina respectively.
$58 \%$ greater than that of a Goldmann lens, and its lateral and axial magnification are greater than those of the Goldmann lens by $3 \%$ and $7 \%$ respectively. But the working field of view of a Mainster lens is $14 \%$ less than that of the Panfundoscope lens, so the peripheral retinal area it spans is $21 \%$ less than that of a Panfundoscope lens. Since the Mainster lens has both high magnification and a wide field of view, it is useful for detecting retinal thickening, following angiographic landmarks to retinal targets, and performing focal as well as panretinal photocoagulation.

The Panfundoscope and Mainster lenses share a common disadvantage. ${ }^{914}$ As noted above, anterior segment irradiance may exceed retinal irradiance for a $1000 \mu \mathrm{m}$ spot size setting, increasing the risk of cornea or lens damage if ocular media are hazy. ${ }^{914}$ In this situation spot size settings should be restricted to $500 \mu \mathrm{m}$ or less. Both lenses also share a slight sensitivity to ametropia, as shown in Table III. Changes in magnification are probably not clinically significant, but for a +3 dioptre hyperopic patient the viewable peripheral retinal area is decreased by $18 \%$ and $21 \%$ for Panfundoscope and Mainster lenses respectively.

The accuracy of the preceding calculations is limited by that of the standard eye model we employed. Within that constraint, Tables I-IV offer a self-consistent comparison of contemporary ophthalmoscopic contact lens performance.

This research was supported in part by the Kansas Lions Sight Foundation Inc, and Research to Prevent Blindness Inc. M A Mainster does not have a proprietary interest in any ophthalmoscopic lens or manufacturer. J L Crossman, P J Erickson, and G L Heacock are employees of Ocular Instruments Inc, which manufactures the Krieger and Mainster ophthalmoscopic lenses.
frich

1 Mainster MA, White TJ, Tips JH, Wilson PW. Retinal temperature increases from intense light sources. $\mathcal{F}$ Opt Soc Am $(A)$ 1970; 60: 264-70.

2 Mainster MA. Laser light, interactions and clinical systems. In: L'Esperance FA Jr, ed. Ophthalmic lasers: photocoagulation, photoradiation and surgery. 3rd ed. St Louis: Mosby, 1989; 1: 61-77.

3 Goldmann H. Zur Technik der Spaltlampenmikroskopie. Ophthalmologica 1938; 96: 90-7.

4 Schlegel HJ. Eine einfache Weitwinkeloptik zur spaltlampenmikroskopischen Untersuchung des Augenhintergrundes. Doc Ophthalmol 1969; 26: 300-8.

5 Lobes LA, Benson W, Grand MG. Panfunduscope contact lens for argon laser therapy. Ann Ophthalmol 1981; 13: $713-4$.

6 Blankenship GW. Panretinal laser photocoagulation with a wide-angle fundus contact lens. Ann Ophthalmol 1982; 14: 362-3.

7 Dieckert JP, Mainster MA, Ho PC. Contact lenses for laser applications. Ophthalmology 1984; 91 (suppl): 79-87.

8 Yannuzzi LA, Slakter JS. Macula photocoagulation lens. Am f Ophthalmol 1986; 101: 619-20.

9 Rol P, Fankhauser F, Kwasniewska S. New contact lens for observation and coagulation of the retina and choroid. $A m \mathcal{F}$ Ophthalmol 1988; 105: 479-82.

10 Le Grand Y, El Hage SG. Physiological optics. Berlin: Springer, 1980: 57-69.

11 Pomerantzeff O, Pankratov M, Wang G-J. Wide-angle optical model of the eye. Am F Optom Physiol Opt 1984; 61: 166-76.

12 Campbell CJ, Koester CJ, Rittler MC, Tackaberry RB Physiological optics. New York: Harper and Row, 1974: 16371

13 Meyer-Arendt JR. Introduction to classical and modern optics. 2nd ed. Englewood Cliffs: Prentice-Hall, 1984: 128-37.

14 Birngruber R, Lorenz B, Weinberg W, Greite J-H, Gabel V-P. Komplikationen bei der Laserkoagulation durch das Panfunduskop. Fortschr Ophthalmol 1983; 79: 434-7. 